\title{
Weekend School Face- to-Face tutorials Apathy in ODL. A Case of ZOU Midlands Region: Zimbabwe
}

\author{
Dr Kurebwa Mercy
}

\author{
Department of Educational Studies, Zimbabwe Open University, Zimbabwe \\ mtkurebwa@gmail.com
}

Doi:10.5901/ajis.2014.v3n6p313

\begin{abstract}
This study was set to investigate views of students and lecturers on students' poor attendants to weekend schools. The sample constituted 20 students who participated in in-depth interviews and two student focus groups of eight making a total of 36 participants. Data collected through individual interviews, focus groups and document analysis were thematically analysed. It was revealed through this study that financial problems, social problems, poor student's perceptions, poor lecturer's competences and poor communication skills hinder students from attending weekend school tutorials. It was also revealed that ZOU interactive modules were so well written that some students students saw no reason of attending weekend school face-toface tutorials. The study recommends conducting weekend schools at district centres, providing e-learning face-to-face tutorials, monitoring part-time tutors by programme coordinators and the quality assurance personnel and assist them conduct themselves professionally, making at least one weekend school compulsory, inducting students on the role of tutorial sessions so that they hold clear perceptions, scheduled weekend schools to be part of the students' registration packages and e-mailing all students on the scheduled weekend schools.
\end{abstract}

Keywords: - Open and Distance Learning (ODL), face-to-face tutorials, weekend schools, instructional strategies,

\section{Introduction}

Open and distance learning is becoming an accepted and indispensible part of the mainstream educational systems in both developed and developing countries (UNESCO, 2004.(Perraton, et al (2001) defines distance education as, "An educational process in which a significant proportion of teaching is conducted by someone far removed in space and time from learners. ODL represents approaches that focus on opening access to education and training provision, freeing learners from the constraints of time and place and offering learning opportunities to individuals and groups of learners (UNESCO, 2002).

ODL employs a wide variety of instructional learning strategies which include ICTs, print modules and face-to-face interaction. Like in many other ODL Universities, ZOU uses print modules as the main mode of delivery. Students are expected to read the modules in advance and identify problems that tutors can help to solve during weekend school faceto-face tutorials. The tutorials are provided at the rate of 6 hours per module per semester. Attendance to tutorials is not compulsory in the Zimbabwe Open University. However, despite the important role of weekend school tutorials, students' poor attendance to weekend school tutorials has propelled the researcher to conduct this study.

\section{Literature Review}

\subsection{Role of face-to-face tutorials}

Face to face tutoring replaces the contact offered in conventional education. Moore and Tait (2002) argue that tutorial delivery models in ODL attempt to minimize the physical separation of learners from tutors and from other learners. This is done by utilizing learners' social and work environments and by continuously exploring learning opportunities that overcome barriers caused by personal obligations such as work commitments and geographical location. The objectives of dialogue through face-to-face contact with ODL students are as follows:-

- stimulating student dialogue

- motivating students

- helping students overcome academic difficulties and academic problems of studying through ODL (Coll, 
2013).

Face-to-face tutorials supplement printed materials in ZOU and provide students with ongoing dialogue that facilitates active learning and also provide the support they need. A student should be fully active in learning (Bork and Gunnarsdottir, 2001). The focus of tutorials is to enable a two way communication between tutors and students. According to Dzikaria and Walker (2003) infrequent face-to-face meetings between teachers and distance learners causes frustration and sometimes impede the learning process. Learners suffer from feelings of loneliness and non ownership when no instructor is present. ODL students need tutor guidance to channel their enquiries and to discuss course materials in greater depth.

Tutorials in ZOU involve discussions and application of key concepts. Tests are also administered in some programmes. Tutors therefore need to master course content (Cruickshank et al, 2009). If the tutor fails to master the subject matter, it might deter students from attending weekend school face-to-face tutorials.

\section{Problem Statement}

ZOU has a blend of interactive print as well as the 6 hour per module per semester tutor sessions. Despite the crucial role played by weekend school face-to-face tutorials in ODL, the tutorials appeared to face challenges of poor attendance. A perusal of documents indicated that there was 0 to $50 \%$ weekend school attendance in most programmes. The purpose of this paper is to explore the weekend school face-face tutorial impediments in ODL.

\section{Research Objectives}

- To explore the challenges faced by ODL students in attending face-face tutorials.

- Make suggestions on how to mitigate the challenges.

\section{Research Questions}

- What challenges do students meet in attending face-to-face tutorials in ODL?

- How can the challenges be mitigated?

\section{Research Methodology}

The research is situated in the interpretive qualitative research paradigm which allows the researcher an in-depth understanding as experienced by participants in their setting. Qualitative research is an approach that advocates the study of direct experience taken at face value (Cohen et al, 2007). It allows the researcher to derive a deeper understanding of the situation. A case study was adopted in this study because the study was centred on ZOU Midlands Region only.

The participants were purposefully selected to participate in individual interviews and focus groups. Zint and Montgomery (2007:3) state that, "Purposive sampling is a non-random method where the researcher selects information rich cases for study in-depth." Individual in-depth interviews were conducted with 20 students. Two focus groups of eight students each were also conducted. Documents to show students' attendance were also perused. It is better to select a variety of research methods when approaching a problem than rely on one single method (Creed et al., 2004:60).

Data was analysed through the use of analytic techniques derived from qualitative research, primarily thematic analysis (Manning and Luyt, 2011). Data analysis involves breaking up data into manageable themes, patterns, trends and relationships (Mouton, 2005:108). Themes that emerged from the data were identified.

\section{Findings and Discussions}

The study focused on the poor attendance of students to weekend school face-to-face tutorials. Several factors that impinge students from attending face-to-face weekend school tutorials were revealed. These included socio-economic factors, scheduling of weekend school tutorials, poor student perceptions of tutorials, lack of commitment and competences from tutors and unethical practices by some part-time tutors during weekend schools. Some modules were so clearly written that some students saw no reason of attending weekend schools. 


\subsection{Socio-economic factors}

The study revealed that financial constraints played a greater part in impeding student attendance to weekend school tutorial sessions. ZOU Midlands Region is big and students are widely dispersed. Tutorials are conducted in Gweru Urban and students from rural areas find it difficult to raise funds for transport, accommodation and food during the weekend school face-to-face tutorials. The study also revealed that attendance to weekend schools was better during the first weekend schools. This was because the weekend schools were scheduled within a close proximity to each other and students failed to afford transport and other related expenses to attend the subsequent tutorial sessions. Students incur various costs related or unrelated to tutorials and the chief among them being transport (Chikoko and Chiome, 2013).

Social factors were also mentioned as contributing to poor attendance to weekend schools. These included illnesses, church commitments and work related commitments. These were mentioned by $30 \%$ of the participants.

\subsection{Poor perceptions of students on tutorials}

More than $50 \%$ of the students indicated that they sometimes do not attend weekend schools because some tutors did not lecture to them until they understood the modules. One student lamented, "Tutors should teach us until we understand. In fact tutors have to repeat the concepts until we understand". The other student also made the following comment, "If a tutor does not lecture to me, I don't see the reason for attending tutorials". It also emerged from the study that the majority of the students come for weekend schools before having attempted to read the modules. The sentiments were echoed by one student who said "I read my module towards examinations or when writing assignments. I am too busy" While some students hold such perceptions on face-to-face weekend tutorials, the perceptions are contradictory to the expectations of the ZOU face-to-face tutorial delivery mode. A student approach to teaching should be adopted to enable a deeper understanding of phenomena. Students tend to lack satisfaction in the manner the face-to-face tutorials are conducted. Satisfaction is a summary of psychological state resulted when emotion surrounding disconfirmed expectation coupled with the consumer prior feeling about consumption experience (Olive, 1981; Herman, 2012).

\subsection{Lack of Commitment/ competence from tutors.}

The study revealed that some tutors lacked commitment to their jobs. According to some students in the focus group, other tutors exhibited lack of preparedness during weekend school tutorial sessions. Some tutors would read the module to the students while others would read notes. The study also revealed that certain tutors would complain about their conditions of service during tutorial sessions. As a result, students tended to view such behaviour from lecturers as a waste of time. One student commented, "I am very literate and a tutor does not have to read the module on my behalf. I also expect the tutor to go deeper into the subject matter".

It also emerged from the study that some tutors failed to provide any new information outside that provided in the module. Certain tutors provided students with limited data during weekend schools. Students in a focus group highlighted that the tutors advised the students who needed more information to attend their extra-lessons for a fee. In this respect, students saw no reason to attend weekend tutorial sessions, but rather make arrangements with the tutors for extratuition.

\subsection{Clearly written modules}

ZOU uses print modules as the main mode of delivery and face-to-face tutorials are meant to complement the print modules. It emerged from the study that a number of modules were clearly written in such a way that some students saw no reason for attending weekend schools. From the statistics of weekend school attendance, it was observed that the attendance was better for students in their first and second semesters. When asked why the scenario was like this, one student echoed, "I now have the skills to read and understand the module and I see no reason to continue attending weekend school tutorials"

\subsection{Poor Communication}

Students indicated that poor communication with students led them to fail to attend weekend school face-to-face tutorials. Weekend school notices were displayed on notice boards at the regional offices and district centres at times well after the 
registration period. However, some students indicated that after registration others never bothered to check on the notice boards for weekend school timetables. This resulted in some students failing to attend weekend schools.

\section{Conclusions}

The major purpose of this study was to explore the weekend school face-to-face tutorial impediments in ODL. Based on the analysis made, the following results were found:-

- Financial problems were a major impeding factor which hindered ODL students to attend weekend school tutorials especially for students from rural areas who had to bear costs for transport, accommodation and other related costs.

- Social problems such as illnesses, bereavement in the family, work related commitments and church commitments also deterred students from attending weekend schools.

- Lack of tutor competences and commitments frustrated students leading them not to attend weekend school tutorials.

- The students' misconceptions on the role of tutorials resulted in students not attending weekend schools. Some students expected a teacher centred approach where the tutor lectures. It is only human nature to view things in certain ways and act accordingly (Ojo, 2000).

- Some of the ZOU interactive modules were so well written that some students saw no reason of attending lectures after having read the modules.

- Communication on weekend school tutorials was sometimes not effective to reach all the students.

\section{Recommendations}

Based on the findings of the study, this study comes up with the following recommendations:-

- Conducting weekend schools at district centres.

- Providing e-learning face-to-face tutorials.

- Monitoring part-time tutors by programme coordinators and the quality assurance personnel and assist them conduct themselves professionally.

- Making at least one weekend school tutorials compulsory.

- Inducting students on the role of tutorial sessions so that they hold clear perceptions.

- Scheduled weekend schools to be part of the students' registration packages.

- E-mailing all students on the scheduled weekend schools.

\section{References}

Bork, A. and Gunnarsdottir, S . (2001) Tutorial distance learning: Rebuilding our educational system. New York, NY: Kluwer.

Cohen,L.,Manion,L.\&Marrison,V. (2007).Research Methods in Education: Abingdon,Oxon Park,.

COLL,(2013) Face -to Face Tutoring Manual: Centre for Lifelong .Polytechnic of Namibia.

Chikoko,V.and Chiome,C. 013)Quality of tutorials and distance learning. Exploring experiences of Zimbabwe Open University.African Educational Research Journal.Vol.1(2) (pp.152-160).

Creed,C. etal (2004) Practioner Research and Evaluation Skills in Open and Distance Education.Common Wealth of Learning.

Cruickshank, D.R., Jenkins, D.B., \& Metcalf,K.K. (2009). The act of teaching. NewYork: McGraw-Hill.

Dzakiria, H. \& Walker, R. (2003). Understanding the Culturally Diverse - Malaysian Distance Learners: Does Culture has a Role and an Effect on Learning and Practice in Distance Education,Malaysian Journal of Distance Education, 5 (1), (pp. 95-107).

Hernman (2012) Face-to-Face Tutorials in ODE and Student Satisfactioin Indonesia.The Asian Society of Open and Distance Education,ISSN 1347-9008 Asian J D E 2012 vol 10, no 2, pp 4 - 13.

Manning,R \&Luyt (2011)Qualitative Data Analysis :A practical Introduction.Sage Publication

More M and Tait (2002). Open and Distance Learning: Trends, Policy and Strategy considerations. Paris: UNESCO

Mouton,J.(2005)How to Succeed your Masters and Doctoral Studies.Pretoria;Van Schaik.

Ojo O. D (2000). Knowledge, Attitudes and Practices of Parents and Teachers in relations to Adolescents' Reproductive Health Training in Osun State, Nigeria. Unpublished Ph.D Dissertation. Faculty of Education, Obafemi Awolowo University: Ile-Ife, Nigeria.

Oliver, R. (1981). Measurement and evaluationof satisfaction process in retail settings. Journal of Retailing, 57, 25-48.

Peratton, H. \& Hulsmann T (2003) Planning and Evaluating Systems of Open and Distance Learning, Report to the DFID by the IRFOL, Cambridge: International Research foundation for Open Learning

Zint,M \&Montgomery ,N (2007)Purposeful Sample. London. Sage publication.

UNESCO (2002).. Information and Communication Technologies in Teacher education: A Planning Guide. Paris. UNESCO. 